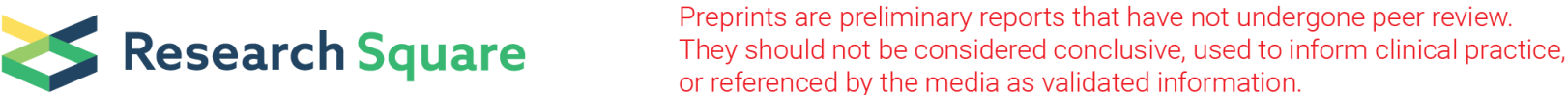

\section{Surface Plasmon Resonance (SPR) based biosensor using MXene as a BRE layer and Magnesium Oxide (MgO) as an Adhesion layer}

AKASH SRIVASTAVA ( $\square$ akash2011srivastav@gmail.com )

MNNIT Allahabad: Motilal Nehru National Institute of Technology https://orcid.org/0000-0002-20858085

\section{Y.K. Prajapati}

Motilal Nehru National Institute of Technology

\section{Research Article}

Keywords: Surface Plasmon Resonace (SPR), Oxide adhesion layer, OSLR polymer, Sensitivity, Figure of Merit, Long Range-SPR (LR-SPR)

Posted Date: March 2nd, 2021

DOI: https://doi.org/10.21203/rs.3.rs-172711/v1

License: (c) (i) This work is licensed under a Creative Commons Attribution 4.0 International License. Read Full License

Version of Record: A version of this preprint was published at Journal of Materials Science: Materials in Electronics on July 8th, 2021. See the published version at https://doi.org/10.1007/s10854-021-06436-x. 


\section{Abstract}

In this paper a plasmonic sensor consist of bimetallic layer of $\mathrm{Ag}$ and $\mathrm{Au}$, a nono-thin layer of two dimension material MXene and a thin layer of Magnesium oxide ( $\mathrm{MgO})$ is proposed to operate in visible region. By using Kretschmann configuration based structure and transfer matrix method, the change in the refractive index of liquid Biosample have been observed at a fixed incident wavelength. By using the distinctive properties of $\mathrm{Ti}_{3} \mathrm{C}_{2} \mathrm{~T}_{\mathrm{x}}$ MXene and $\mathrm{MgO}$ we have investigated the performance of Surface Plasmon Resoance (SPR) biosensor. Significant performance parameters like Sensitivity, Figure of Merit (FoM) and Detection Accuracy (DA) calculated for different cases to prove the capability of proposed sensing structure. We also compared the sensitivity and sharpness of SPR curve obtained when using conventional adhesion layers like titanium ( $\mathrm{Ti}$ ), chromium ( $\mathrm{Cr}$ ), tantalum ( $\mathrm{Ta}$ ). A detailed investigation is carried out to observe the role of polymer as an adhesion layer and its thickness impact on FoM and resonance angle sharpness. The concept of Long range SPR (LR-SPR) and Short range SPR (SR-SPR) also discussed.

\section{Full Text}

Due to technical limitations, full-text HTML conversion of this manuscript could not be completed. However, the latest manuscript can be downloaded and accessed as a PDF.

\section{Figures}

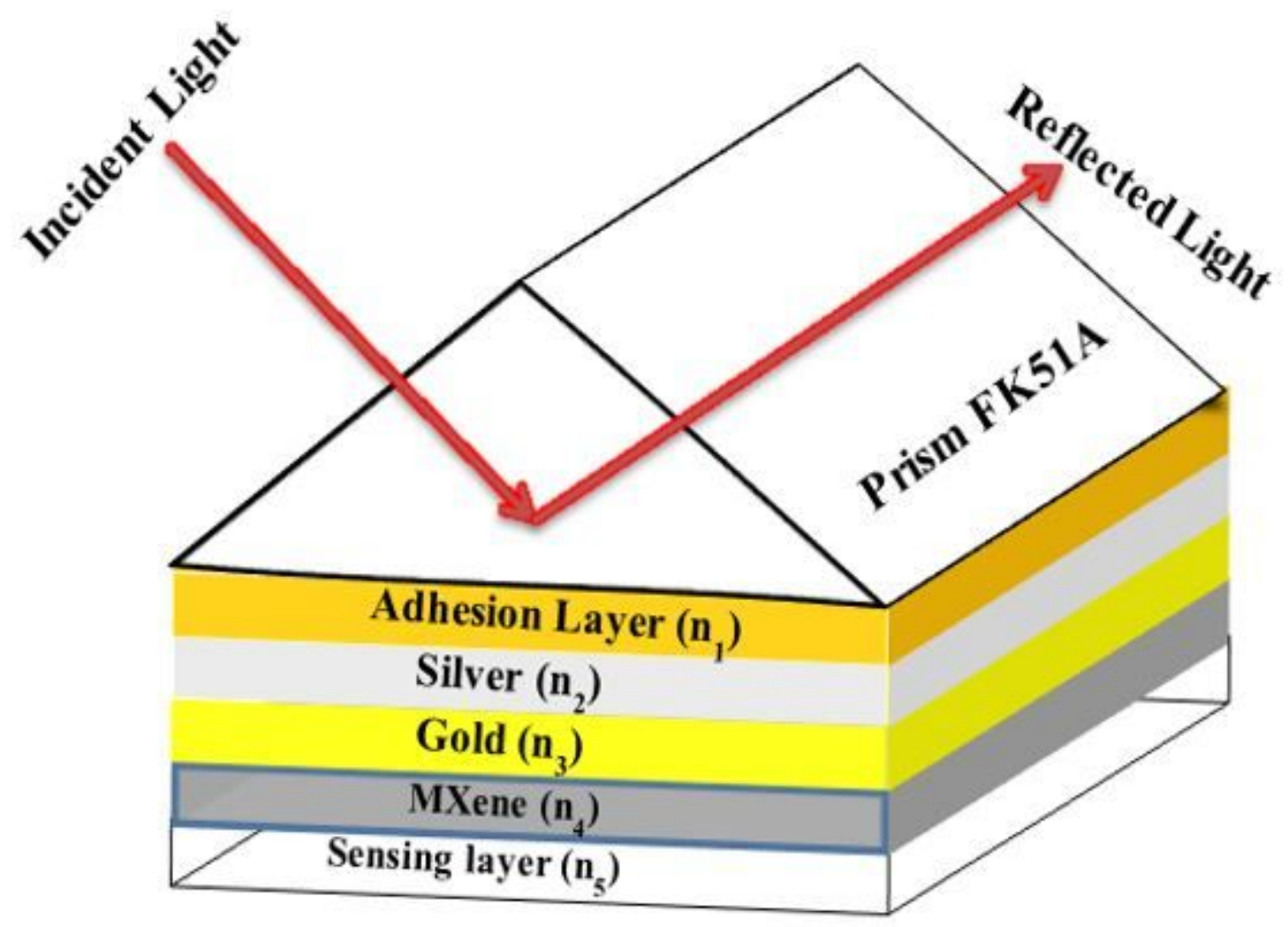


Figure 1

Schematic diagram of proposed SPR based sensor
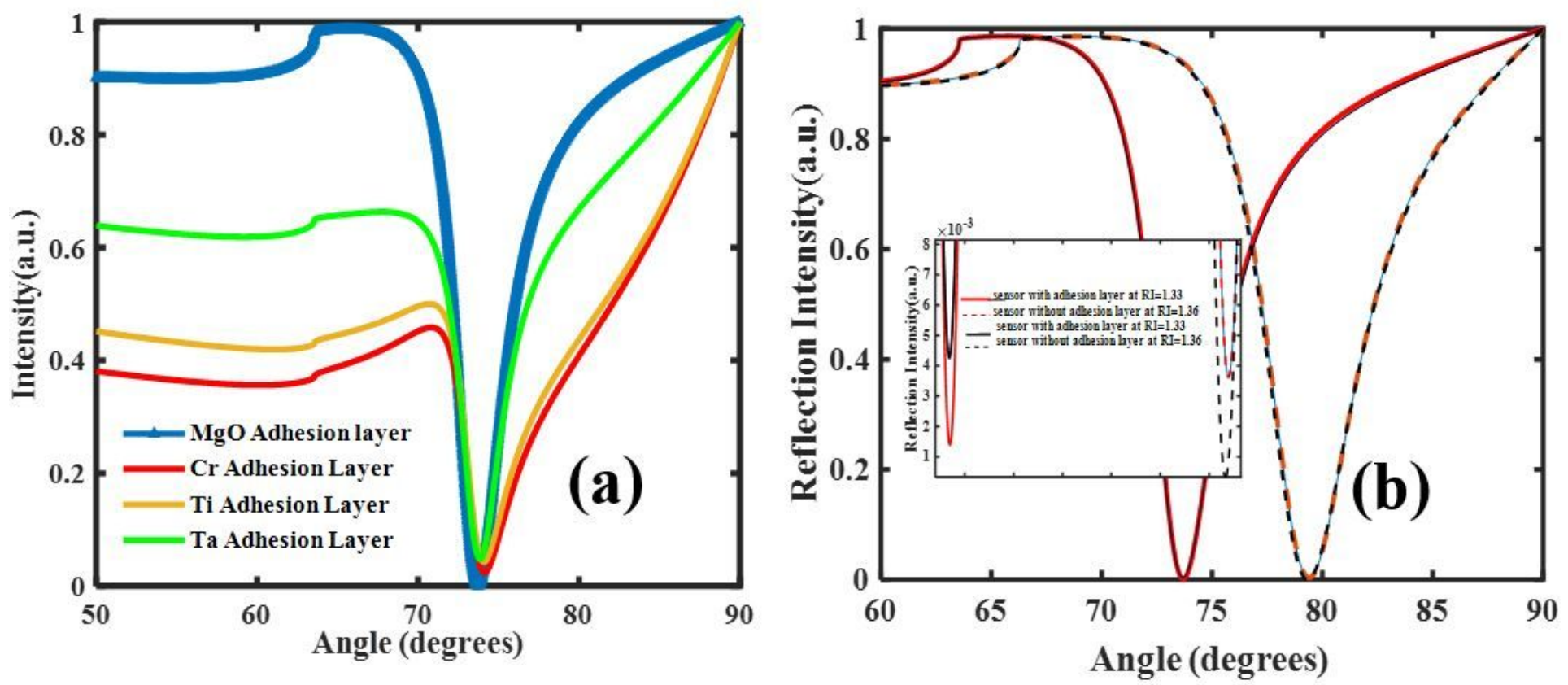

Figure 2

Adhesion layer effect of SPR based biosensor (a) comparison of SPR angle when MgO (oxide) used as a adhesion layer with metallic thin film based sensor (b) shift in resonance angle with and without using oxide adhesion layer 


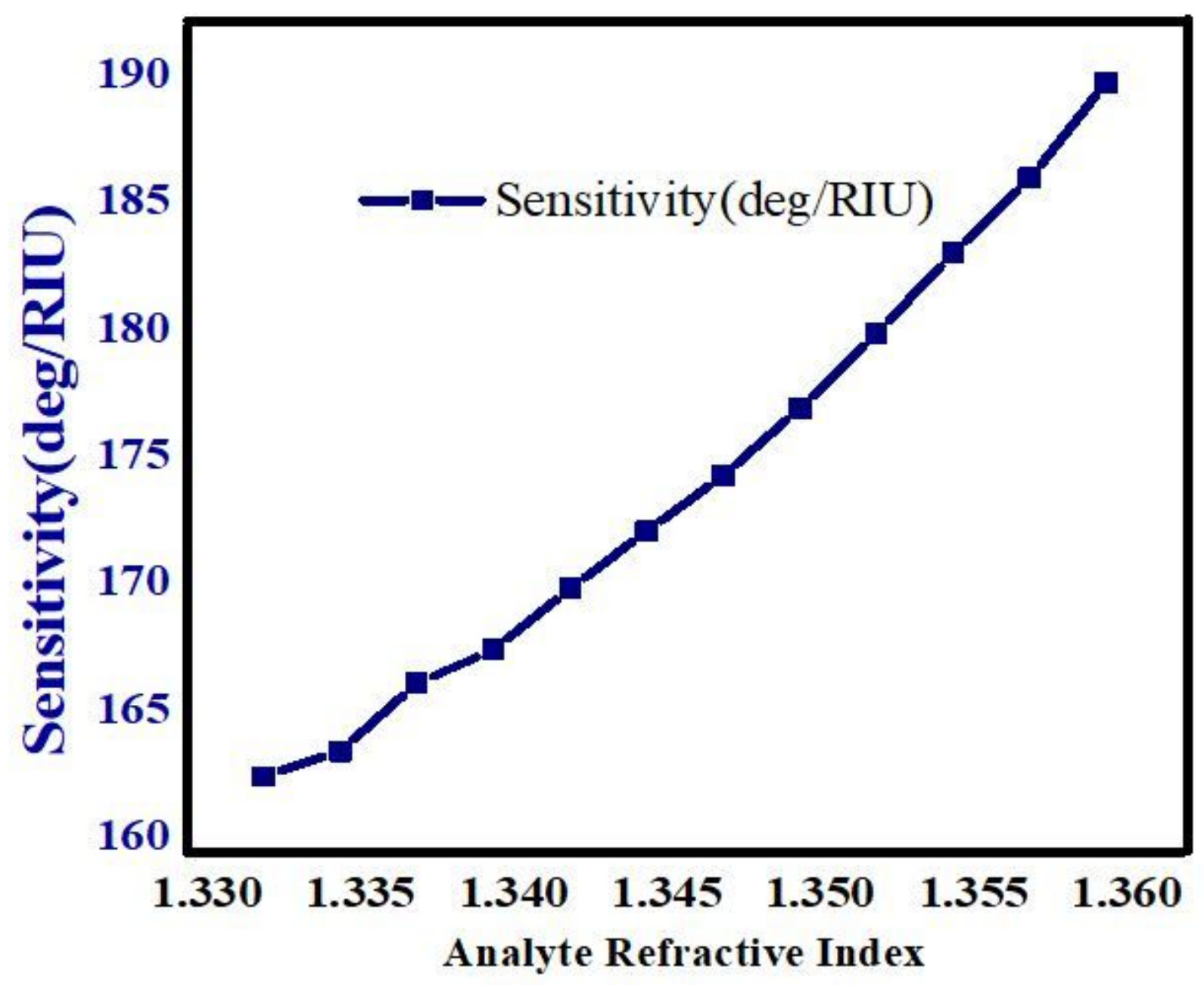

Figure 3

variation of sensitivity with respect to analyte refractive index 


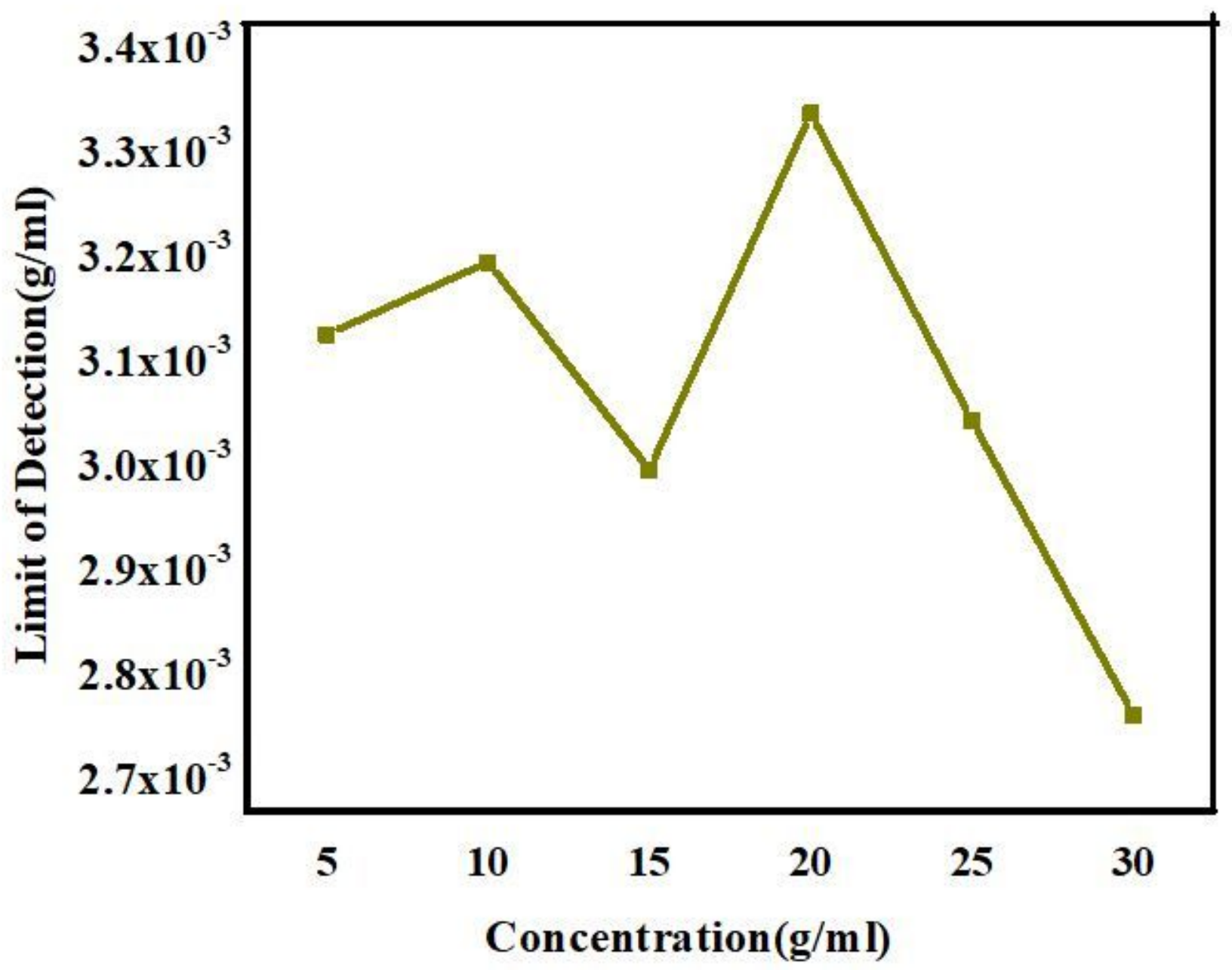

Figure 4

Limit of detection (LOD) variation with sugar concentration. Here the reference value of concentration from $0 \%$

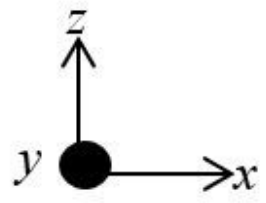

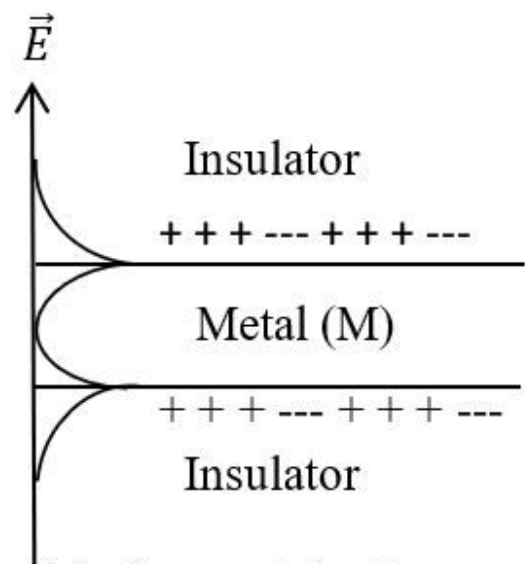

(a) Symmetric plasmon mode

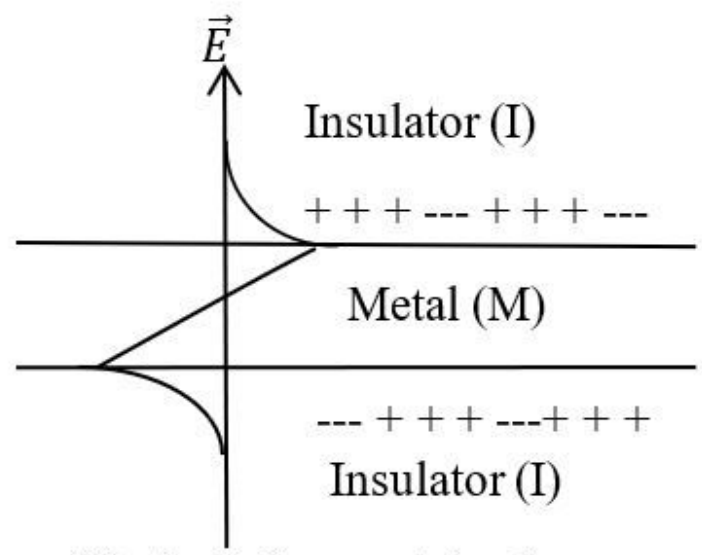

(b) Anti-Symmetric plasmon mode

Figure 5 
modes of surface plasmon in Insulator metal insulator (IMI) type structure

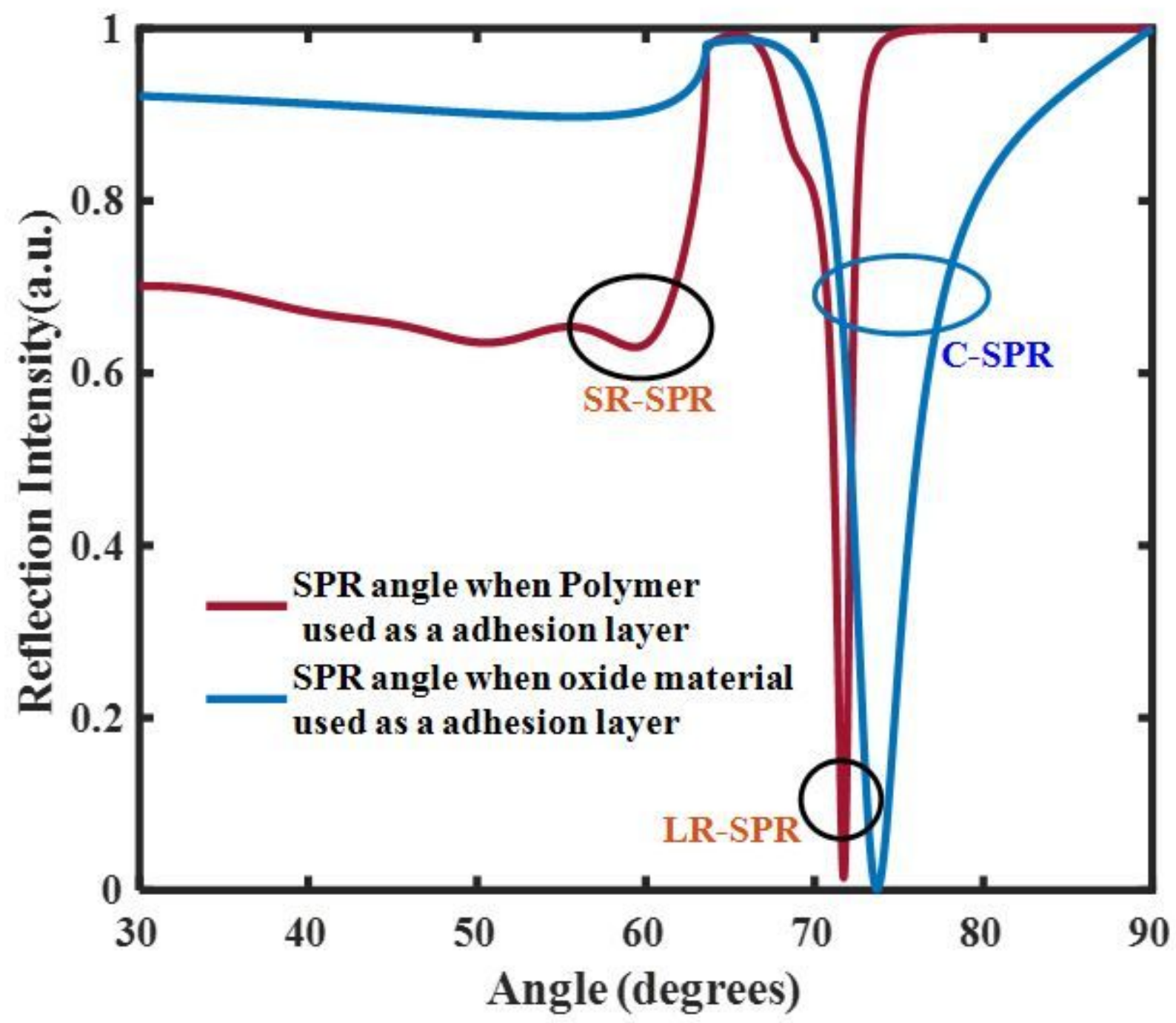

Figure 6

resonance angle analysis for liquid analyte between C-SPR and LR-SPR 

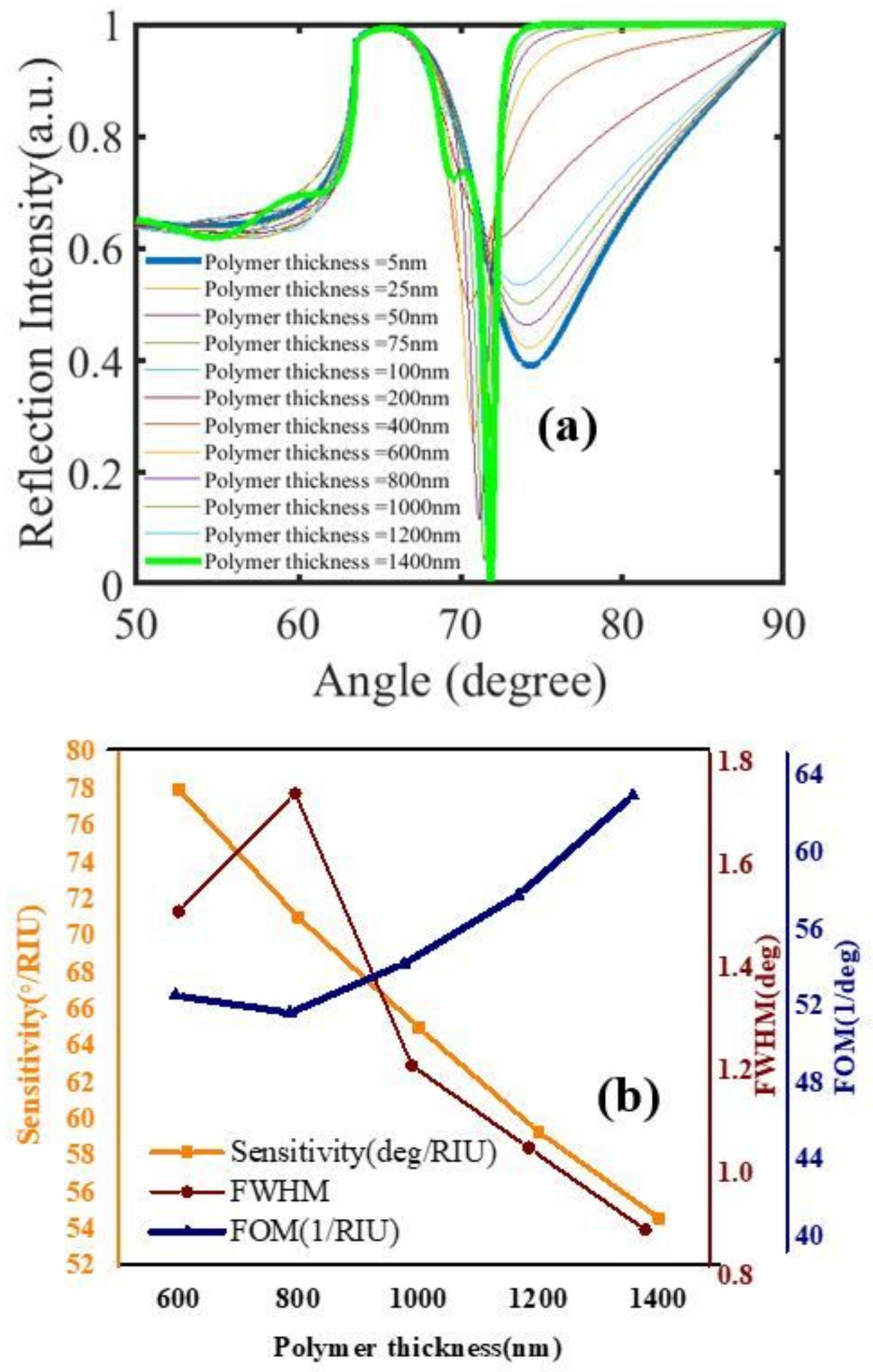

Figure 7

Polymer adhesion layer thickness dependent SPR angle(a) Resonance angle position by changing polymer layer thickness (b) performance parameter analysis 